\title{
Vitamin D deficiency showed association with knee osteoarthritis in Tamilnadu population - A pilot study
}

\author{
Regupathy Annamalai ${ }^{1, *}$, Amar Nagesh Kumar ${ }^{2}$ \\ ${ }^{\mathbf{1}}$ Associate Professor, ${ }^{\mathbf{2}}$ Assistant Professor, ${ }^{\mathbf{1}}$ Dept. of Orthopedics, ${ }^{\mathbf{2}}$ Dept. of Biochemistry, Karpaga Vinayaga Institute of Medical
} Sciences and Research Center, Madurantagam, Tamilnadu, India

*Corresponding Author:

Email: annuregu@yahoo.com

\begin{abstract}
Introduction: Aim of the study is to measure serum 25 - hydroxy vitamin D levels in patients with knee osteoarthritis in comparison with age matched healthy controls and also to assess the association of 25-OH vitamin with osteoarthritis.

Materials and Methods: The study population consists of 240 patients divided into two groups, Group 1 and Group 2 . Group 1 with 120 subjects with clinical features of knee osteoarthritis served as controls and Group 2 consists of 120 patients of patients diagnosed with knee osteoarthritis. Serum 25-OH vitamin D was measured in all the participants by the ELFA method and concentrations $<10 \mathrm{ng} / \mathrm{ml}$ was considered as deficient.

Results: In Group 1, 57(46.5\%) were males and 63 (53.5\%) females, while in Group 2, 57(45.5\%) were males and 63 (54.5\%) females. Distribution of vitamin D status according to age, BMI and gender was also made and compared between the groups. Number of patients $<60$ years were 55 and 56 respectively in Group 1 and Group 2. Serum 25-OH vitamin D deficiency was observed in 67 $55.8 \%)$ patients in Group 2 versus $15(12.5 \%)$ of Group B $(P=0.001)$. Further analysis of subgroups, revealed that the mean serum $25-\mathrm{OH}$ vitamin D level in Group 2 aged $<60$ years was significantly lower than Group $1(8.2 \pm 1.1$ vs. $9.2 \pm 0.8$ $\mathrm{ng} / \mathrm{ml}, P<0.05)$.

Conclusion: The present study findings showed a significant association between serum 25-OH vitamin D deficiency and in patients with knee osteoarthritis aged $<60$ years. Screening of serum $25-\mathrm{OH}$ vitamin D measurement in patients with symptoms suggestive of knee osteoarthritis is recommended as it showed association with knee osteoarthritis.
\end{abstract}

Keywords: 25 - OH Vitamin D, Osteoarthritis, Body mass index, Age, Knee joint pain.

\section{Introduction}

The prevalence of vitamin $\mathrm{D}$ deficiency is the burning topic worldwide. Vitamin D deficiency is a under diagnosed medical condition since a significant proportion of the population in many countries and regions around the world have low serum 25-OH vitamin $\mathrm{D}$ levels. ${ }^{1-4}$ The serum level of 25-hydroxy vitamin D depends on various parameters such as ultraviolet irradiation (determined by the time of day) to skin, skin pigmentation, season, ${ }^{5-7}$ latitude, age, dietary habits, gender, obesity, and many others factors. ${ }^{6-9}$ It is known that vitamin $\mathrm{D}$ has role in mineralization, demineralization, remodeling, and maintenance of bone. Therefore its deficiency may be implicated in the pathogenesis of osteoarthritis (OA). ${ }^{10,} \quad{ }^{11}$ The pathogenesis of OA is still unclear. Recent studies on changes in sub-chondral bone remodeling phases of bone absorption and of bone sclerosis may be responsible for the cartilage damage. ${ }^{12-14}$ The reason behind these changes in the cartilage and bone is that low levels of 25-hydroxyvitamin D.

Knowledge of the serum status of 25-OH vitamin $\mathrm{D}$ may provide additional information to recognize patients at risk for progression of OA knee. The objective of this study is to evaluate the serum $25-\mathrm{OH}$ vitamin $\mathrm{D}$ status in patients with knee OA scheduled for joint replacement along with healthy individuals for comparison. And also to find out association between serum $25-\mathrm{OH}$ vitamin D levels with age and body mass index (BMI) and with the knee osteoarthritis. Since, there are very few studies available on the association of 25-OH vitamin D in knee osteoarthritis patients, the present study was undertaken.

\section{Materials and Methods}

Study Setting and Design: This is a pilot study conducted in and around the Chennai city and rural places of Tamilnadu population. Subjects were selected during the medical camps conducted by our teaching hospital in and around the Chennai city and rural places of Tamilnadu. The study was approved by the institutional ethics committee. An informed consent was obtained from all the participants after explaining the purpose of the study. The study consists of 120 ages matched controls (Group 1) and 120 patients with knee osteoarthritis as cases (Group 2). Further study the subjects were divided into two sub groups based on age ( $<60$ years and $>60$ years) in both group 1 and group 2 . Based on body mass index (BMI) there are four subgroups i.e, BMI $<20,20-25,26-30$ and $>30$ in each group. Based on vitamin D status there are three subgroups in each group.

Inclusion Criteria: Patients who presented with knee joint pain to the medical camps conducted by the department of Orthopaedics, Karpaga Vinayaga Institute of Medical Sciences and Research were recruited for the study. American College of Rheumatology classification was considered as standard for the diagnosis of knee osteoarthritis. ${ }^{13,14}$ Subjects of the control group were selected over the 
same period patients without non skeletal symptoms and had no clinical features of knee OA based on history and clinical examination.

Exclusion Criteria: Patients with history of rheumatic diseases other than osteoarthritis, chronic kidney diseases, gastrointestinal disorders, pulmonary systems, and persons on anticonvulsant drugs were excluded from the study. Stage 4 Kelegren-Lawrence stage, severe radiographic knee osteoarthritis, and those with knee joint instabilities were also excluded from the study. Patients with physical disabilities were excluded from the study.

Methodology: Vitamin D status was measured by the serum concentration of $25-\mathrm{OH}$ vitamin $\mathrm{D}$ which has a reasonably long half life in the circulation. Measurement of serum 25-OH vitamin D was made by ELFA using fully automated minividas (Biomeriux, Germany) hormone analyzer. Based on the results obtained vitamin D status was categorized into 3 groups as serum $25-\mathrm{OH}$ vitamin D levels $<10 \mathrm{ng} / \mathrm{ml}$, between 10-29 ng/ml, and $30-100 \mathrm{ng} / \mathrm{ml}$, indicating vitamin D deficiency, vitamin D insufficiency and vitamin D sufficiency respectively.

Statistical Analysis: In statistical analysis the mean serum 25-OH vitamin D levels and proportion of serum $25-\mathrm{OH}$ vitamin $\mathrm{D}$ deficiency were determined in both the groups and compared with the age matched controls. Additional subgroup analyses were performed according to age groups of $<60$ years versus $>60$ years. Comparisons were also made with respect to gender and BMI with knee OA as well. Chi square analysis was done to know the association of vitamin D deficiency and knee osteoarthritis. Odds ratio (OR) and its $95 \%$ confidence interval $(95 \%$ CI $)$ was also calculated. The independent effect of serum $25-\mathrm{OH}$ vitamin $\mathrm{D}$ deficiency was determined after adjustment for sex and age using logistic regression analysis. SPSS software version 16.0 was used for statistical analysis.

\section{Results}

There are total 240 persons, recruited for the study. Study population was divided into two major groups, Group 1 (Controls) and Group 2 (OA Cases). Group 1 includes 120 patients without the clinical symptoms of Knee OA and group 2 consists of 120 knee osteoarthritis (OA). Serum 25-OH vitamin D deficiency was observed in $67(55.8 \%)$ patients in Group 2 versus $15(12.5 \%)$ of Group 1 (Table 1). In Group 1, 57(46.5\%) were males and $63(53.5 \%)$ females, while in Group 2, $57(45.5 \%)$ were males and $63(54.5 \%)$ females. Age range of group 1 was $37-69$ years with a mean age of 57.5 years while in Group 2, the age range of subjects was $38-68$ years with a mean age of 58.7 years (Table-1). Further study subjects were divided into two sub groups based on age in both group 1 and group 2 ( $<60$ years and $>60$ years). Number of patients $<60$ years were 55 and 56 respectively in Group 1 and Group 2. Based on body mass index (BMI) there are four subgroups i.e, BMI <20, $20-25,26-30$ and >30 in each group. Based on vitamin D status there are three subgroups in each group (Table 1). In the entire study population serum $25-\mathrm{OH}$ vitamin D deficiency was not homogenously distributed across age but was more frequent in subjects aged $<60$ years compared with $>60$ years particularly in the patient group (Table 1-5). Further analysis of subgroups, showed that the mean serum 25-OH vitamin D level in Group 2 aged $<60$ years was significantly lower than Group $1(8.2 \pm 1.1$ vs. $9.2 \pm 0.8 \mathrm{ng} / \mathrm{ml}, P<0.05)$. In this age group, knee OA was significantly associated with serum $25-\mathrm{OH}$ vitamin $\mathrm{D}$ deficiency. In table 2 comparisons of age, $\mathrm{BMI}$, and 25-OH vitamin D status in controls and osteoarthritis patients was shown. There is no statistical difference with respect to age of the patients in the both the groups. But, statistical significant difference was observed with respect to BMI and serum $25-\mathrm{OH}$ vitamin D in both control group (Group 1) and OA group (Group 2) (Table 2). The association between knee OA and mean serum $25-\mathrm{OH}$ vitamin D levels in patients aged $>60$ years did not reach a significant level among both groups $(7.9 \pm 1.9$ vs. $8.1 \pm 1.5)$. All in all percentage of number of patients with serum $25-\mathrm{OH}$ vitamin D deficiency was significantly higher in Group 2 than Group 1 (67 vs 15, p< 0.001) (Table 3).

In table 3 and table 4 distribution of patients who are under the age of 60 years according to the status of $25-\mathrm{OH}$ vitamin $\mathrm{D}$ in both the groups was shown. Table 5 shows the gender wise distribution of patients according to their vitamin D status. Though there is vitamin $\mathrm{D}$ deficiency in knee osteoarthritis patients who are $>60$ years of age but percentage of number of patients with $25-\mathrm{OH}$ vitamin $\mathrm{D}$ deficiency was not significant (Table 4). Thus, additional analysis in respect to mean serum $25-\mathrm{OH}$ vitamin $\mathrm{D}$ and proportion of serum 25-OH vitamin D deficiency demonstrated a significant difference in age of less than 60 years in Group 2 vs Group 1, but was not significant when compared with 60 years and older (Table 2). Table 6 shows the distribution of patients according to their vitamin $\mathrm{D}$ status and body mass index. In table 7, Odds ratio, $95 \%$ confidence interval $(95 \% \mathrm{CI})$ by logistic regression analysis showing association of serum 25 hydroxy vitamin D deficiency, age, gender, and, BMI with knee osteoarthritis (OA) was shown.

On comparison of data among the same group also, there was a significant difference in $25-\mathrm{OH}$ vitamin $\mathrm{D}$ levels of patients $<60$ and $>60$ years in Group 2 (Table 7 ), while it was not significant in control group. There was an association between serum $25-\mathrm{OH}$ vitamin D deficiency and knee OA which was not statistically significant after adjustment for gender (Table 7). 
Table 1: Baseline characteristics of study population

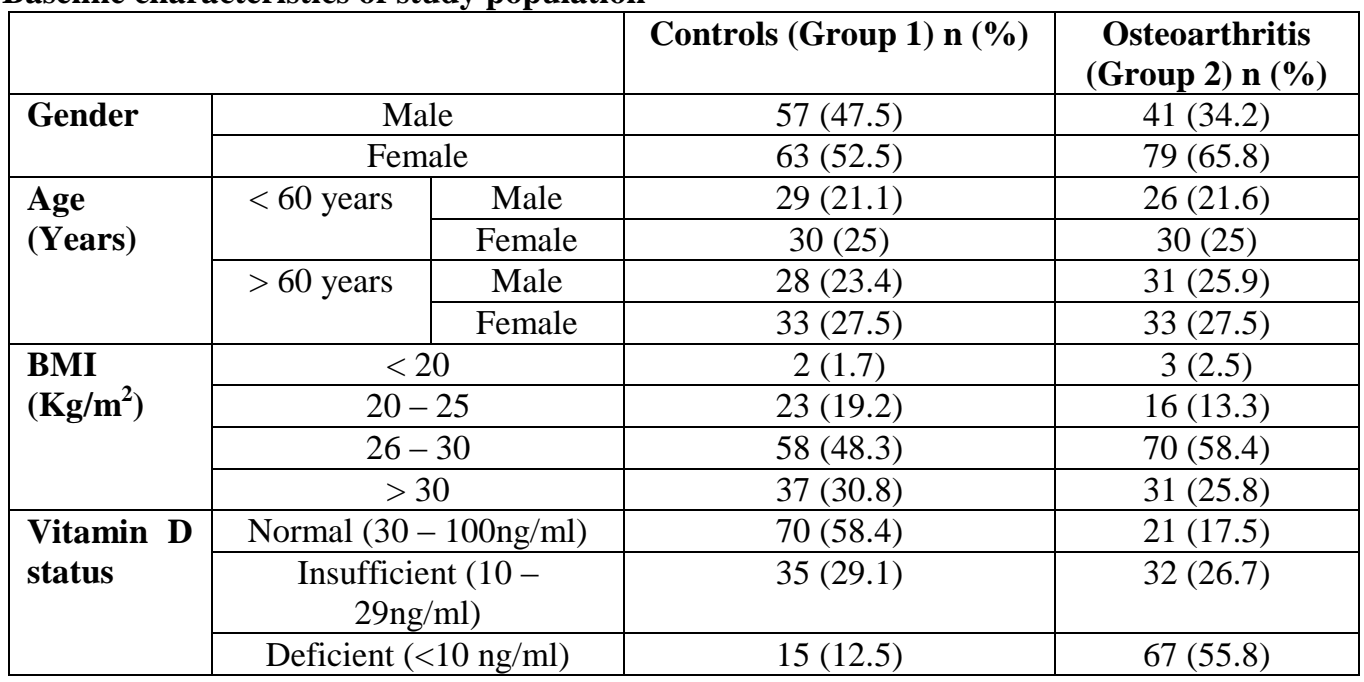

Table 2: Comparison of Age, BMI and 25 - OH vitamin D status in controls and osteoarthritis patients

\begin{tabular}{|l|c|c|c|}
\hline Parameter & $\begin{array}{c}\text { Group 1 } \\
\text { All Controls (n=120) }\end{array}$ & $\begin{array}{c}\text { Group 2 } \\
\text { All Osteoarthritis (n=120) }\end{array}$ & P value \\
\hline Age & $57.5 \pm 9.4$ & $58.7 \pm 9.7$ & 0.33 \\
\hline BMI & $25.4 \pm 7.5$ & $28.5 \pm 6.3$ & $0.006^{*}$ \\
\hline $25-$ OH Vitamin D & $38.2 \pm 15.6$ & $34.4 \pm 11.9$ & $0.03^{*}$ \\
\hline
\end{tabular}

*statistically significant $\mathrm{p}$ value

Table 3: Status of vitamin $D$ in control and cases who are less than 60 year of age

\begin{tabular}{|l|c|c|}
\hline Vitamin D status & Controls $<\mathbf{6 0}$ years $(\mathbf{n}=\mathbf{5 5})$ & Osteoarthritis $<\mathbf{6 0}$ years $(\mathbf{n}=\mathbf{5 6})$ \\
\hline Normal & $35.9 \pm 12.3(\mathrm{n}=39)$ & $33.4 \pm 2.9(\mathrm{n}=12)$ \\
\hline Insufficient & $28.6 \pm 2.5(\mathrm{n}=12)$ & $24.5 \pm 3.5(\mathrm{n}=19)$ \\
\hline Deficient & $9.2 \pm 0.8(\mathrm{n}=04)$ & $8.2 \pm 1.1(\mathrm{n}=25)$ \\
\hline
\end{tabular}

Table 4: Status of vitamin $D$ in control and cases who are greater than 60 year of age

\begin{tabular}{|l|c|c|}
\hline Vitamin D status & Controls $>$ 60 years $(\mathbf{n}=\mathbf{6 5})$ & Osteoarthritis $>$ 60 years $(\mathbf{n}=\mathbf{6 4})$ \\
\hline Normal & $35.9 \pm 7.8(\mathrm{n}=31)$ & $32.5 \pm 8.8(\mathrm{n}=09)$ \\
\hline Insufficient & $26.7 \pm 3.4(\mathrm{n}=23)$ & $22.5 \pm 2.3(\mathrm{n}=13)$ \\
\hline Deficient & $8.1 \pm 1.5(\mathrm{n}=11)$ & $7.9 \pm 1.9(\mathrm{n}=42)$ \\
\hline
\end{tabular}

Table 5: Showing the gender wise distribution of study subjects and their vitamin D status

\begin{tabular}{|l|c|c|c|c|}
\hline \multirow{2}{*}{ Vitamin D status } & \multicolumn{2}{|c|}{ Controls $(\mathbf{n}=\mathbf{1 2 0})$} & \multicolumn{2}{c|}{ Osteoarthritis $(\mathbf{n}=\mathbf{1 2 0})$} \\
\cline { 2 - 5 } & Male $(\mathrm{n}=57)$ & Female $(\mathrm{n}=63)$ & Male $(\mathrm{n}=57)$ & Female $(\mathrm{n}=63)$ \\
\hline Normal & $38.9 \pm 6.8$ & $34.8 \pm 5.5$ & $31.5 \pm 0.7$ & $31.8 \pm 0.5$ \\
\hline Insufficient & $26.8 \pm 3.7$ & $25.7 \pm 6.1$ & $24.6 \pm 3.5$ & $21.7 \pm 1.3$ \\
\hline Deficient & $8.8 \pm 0.6$ & $8.5 \pm 0.4$ & $7.4 \pm 1.7$ & $7.6 \pm 1.2$ \\
\hline
\end{tabular}

Table 6: Showing the 25 - OH vitamin D status according to body mass index

\begin{tabular}{|l|c|c|c|c|}
\hline \multirow{2}{*}{ Vitamin D status } & \multicolumn{5}{|c|}{ BMI (Body Mass Index) } \\
\cline { 2 - 6 } & $\mathbf{2 0}(\mathbf{n}=\mathbf{0 3})$ & $\mathbf{2 0}-\mathbf{2 5}(\mathbf{n}=16)$ & $\mathbf{2 6}-\mathbf{3 0}(\mathbf{n}=\mathbf{7 0})$ & $>\mathbf{3 0}(\mathbf{n}=\mathbf{3 1})$ \\
\hline Normal & Nil & $33.4 \pm 1.6$ & $31.8 \pm 0.8$ & Nil \\
\hline Insufficient & $21.6 \pm 6.2$ & $26.8 \pm 4.2$ & $22.8 \pm 5.9$ & $21.5 \pm 2.7$ \\
\hline Deficient & Nil & $8.9 \pm 1.4$ & $8.3 \pm 1.6$ & $7.9 \pm 2.5$ \\
\hline
\end{tabular}


Table 7: Odds ratio, $95 \%$ confidence interval $(95 \%$ CI $)$ by logistic regression analysis showing association of serum 25-hydroxy vitamin D deficiency, age, gender, and, BMI with knee osteoarthritis (OA)

\begin{tabular}{|c|c|c|c|}
\hline Patients & Variables & $\begin{array}{l}\text { Odds ratio } \\
(95 \% \text { CI })\end{array}$ & P value \\
\hline \multirow[t]{3}{*}{ Total OA patients } & $\begin{array}{c}25-\mathrm{OH} \text { vitamin } \mathrm{D}(<10 \mathrm{vs} \\
>10 \mathrm{ng} / \mathrm{ml})\end{array}$ & $0.16(0.09-1.42)$ & $0.07 *$ \\
\hline & Gender (Female vs Male) & $4.7(1.3-7.8)$ & $<0.001^{*}$ \\
\hline & BMI & $4.3(0.9-7.3)$ & $<0.001^{*}$ \\
\hline \multirow[t]{3}{*}{$\begin{array}{l}\text { OA patients }<60 \\
\text { year }\end{array}$} & $\begin{array}{c}25-\mathrm{OH} \text { vitamin } \mathrm{D}(<10 \mathrm{vs} \\
>10 \mathrm{ng} / \mathrm{ml})\end{array}$ & $0.32(0.11-1.65)$ & $0.04 *$ \\
\hline & Gender (Female vs Male) & $4.5(1.34-8.69)$ & $0.015^{*}$ \\
\hline & BMI & $3.5(1.01-6.38)$ & $0.005^{*}$ \\
\hline \multirow[t]{3}{*}{$\begin{array}{l}\text { OA patients }>60 \\
\text { year }\end{array}$} & $\begin{array}{c}25-\mathrm{OH} \text { vitamin } \mathrm{D}(<10 \mathrm{vs} \\
>10 \mathrm{ng} / \mathrm{ml})\end{array}$ & $1.01(0.49-5.7)$ & 0.89 \\
\hline & Gender (Female vs Male) & $3.21(1.28-8.04)$ & 0.01 \\
\hline & BMI & $4.1(1.2-8.3)$ & $0.003^{*}$ \\
\hline
\end{tabular}

$* \mathrm{p}<0.05$ is statistically significant

\section{Discussion}

Vitamin D deficiency and knee OA occur in elderly people, seen all over the world. ${ }^{12}$ The changes in sub-chondral bone play a vital role in the development of cartilage lesions in OA patients. ${ }^{4,9,8,11}$ At this stage, bone resorption markers are higher and bone formation markers are lower. ${ }^{6,8,13,16}$ Low serum 25-OH vitamin $\mathrm{D}$ increases osteoblastic activity and bone turnover. ${ }^{1,9,14,17}$ Many mechanisms were put forwarded to explain role of vitamin D and alterations in properties of bones in the progression of the disease osteoarthritis. Increasing bone resorption by the elevated levels of parathyroid hormone (PTH) increasing bone turn over, or effect of vitamin D metabolites directly on articular chondrocytes were some of the mechanisms put forwarded to explain the role of vitamin D deficiency in osteoarthritis. ${ }^{3,6,9,15}$

Early structural changes in the joints such as defects in cartilage, decrease in volume of cartilage, expansion of sub-chondral bone, and lesions in bone marrow will appear before the onset of clinical symptoms of OA. Reports and observations from earlier studies provided a rationale for the measurement of serum 25-OH vitamin D levels with appearance of knee $\mathrm{OA}$ in elderly people and encourage supplementation to raise the serum vitamin $\mathrm{D}$ concentration to adequate levels. ${ }^{14-16}$ Epidemiological studies showed an association between dietary intake and serum levels of 25-hydroxy vitamin $\mathrm{D}$ and the progression of hip ${ }^{14,15}$ and knee OA. ${ }^{12,16}$ In a recent study, decreased serum level of 25-hydroxy vitamin D was reported in a significant proportion of patients with OA of hip and knee joints. ${ }^{14,16-19}$ All these epidemiological suggests that by achieving normal serum vitamin D level may prevent or delay loss of cartilage loss and reduce the pain and other symptoms of OA. ${ }^{15-18}$

Observation from studies on knee osteoarthritis evaluated by Cao et al suggested that serum $25-\mathrm{OH}$ vitamin D level play an important role in structural changes of knee osteoarthritis. ${ }^{17}$ In another study done by Bergink et al also, reported three times increased risk of knee $\mathrm{OA}$ and disease progress was associated with serum $25-\mathrm{OH}$ vitamin $\mathrm{D}<20 \mathrm{ng} / \mathrm{ml}$ in the Rotterdam Study. ${ }^{18}$ In patients with hip OA who underwent total hip replacement, 25-hydroxy vitamin D levels were found to have positive correlation with both pre and post-operative Harris hip scores. ${ }^{4,6,16-19}$ Therefore, it is obvious that in patients undergoing total hip replacement vitamin D deficiency was a risk factor for a suboptimal outcome. ${ }^{5,7,19}$ However, few studies failed to show significant association between the low level of serum 25-OH vitamin D and the development of OA. ${ }^{20-22}$ It may be because of low sample size, inclusion of different ethinicity, seasonal variation, their time of exposure to sunlight, usage of sun cream lotions, different dietary habits etc. In the present study these problems were eliminated since all the studied population belongs to South India, Tamilnadu territory. Therefore, earlier studies did not able to establish the association of serum $25-\mathrm{OH}$ vitamin D levels with hip or knee osteoarthritis.

The most important finding of this study is the high prevalence $(55.8 \%$ deficiency and $26.7 \%$ insufficiency; around $78 \%$ ) of low serum levels of 25-hydroxyvitamin $\mathrm{D}$ in a population with $\mathrm{OA}$, in a sunny region like South India of Asian country. This study showed that about 5 patients out of 10 with knee osteoarthritis were vitamin D deficient with serum levels $<10 \mathrm{ng} / \mathrm{ml}$. Several studies have shown a high incidence of vitamin D deficiency in patients with OA of hip or knee. ${ }^{17-19,23} \mathrm{We}$ also tried to correlate serum levels of vitamin D with related anthropometric predisposing factors such as age, gender, and BMI. A significant association with gender was observed, with female patients having lower serum levels of vitamin D.

The findings of the present study are on par with some previous studies $(4,8-10,14,15,19-21)$ showing a significant positive association between serum $25-\mathrm{OH}$ vitamin D deficiency and OA knee in persons less than 
60 years of age and in contrary to some other studies as well. ${ }^{5,7,16-18,17,23}$

In the present study these problems were eliminated since all the studied population belongs to South India, Tamilnadu territory. Therefore, earlier studies did not able to establish the association of serum 25-OH vitamin D levels with hip or knee osteoarthritis. Keeping the limitations of earlier studies in view present study was planned and executed effective to obtain results which are not affected by seasonal variation, diet, and exposure to sunlight or less physical activity due to pain and other confounders because patients and control population recruited for this study were selected from the same geographic territory who had unique racial and cultural backgrounds, with similar diet and sunlight exposure.

\section{Conclusion}

In the present study it is found that there is overall $57 \%$ of vitamin D deficiency in our population. From the present study it can be concluded that there is a significant association between knee osteoarthritis and vitamin D deficiency when compared to control population with respect age, gender and BMI. This association also corresponds with the development of knee cartilage damage in radiographic study. Therefore, identification of high risk subjects and correction of risk factors such as low level serum $25-\mathrm{OH}$ vitamin $\mathrm{D}$ is expected to give beneficial effects, increase in bone mineral density and even decreases fracture risk in the elderly population.

Conflict of Interest: None declared

Financial Support: We did not receive any external funding for this project.

Acknowledgements: Nil

\section{References}

1. Adams JS, Hewison M. Update in vitamin D. J Clin Endocrinol Metab. 2010; 95:471-476. doi:10.1210/jc.20091773.

2. Endocrine Society Practice Guidelines JCEM. Evaluation, treatement and prevention of vitamin D deficiency.2011. http://www.endosociety.org/guidelines/final/upload/FINAL-StandaloneVitamin-D-Guideline.pdf.

3. Holick MF. The vitamin D epidemic and its health consequences. J Nutr. 2005; 135(11):2739S-2748S.

4. Kull M Jr, Kallikorm R, Tamm A, Lember M. Seasonal variance of $25-(\mathrm{OH})$ vitamin $\mathrm{D}$ in the general population of Estonia, a Northern European country. BMC Public Health. 2009; 19(9):22.

5. Holick MF. Vitamin D deficiency. N Engl J Med. 2007; 357(3):266-281.

6. Holick MF, Chen TC, Lu Z et al. Vitamin D and skin physiology: a D-lightful story. J Bone Miner Res. 2007; 22(Suppl 2):V28-V33.

7. Renier JC, Bernat M, Rebel A et al. Study of circulating 25-hydroxyvitamin D. Rev Rhum Mal Osteoartic 1976; 43(7-9):481-489.
8. Davies Tuck ML, Wluka AE, Wang Y, Teichtahl AJ, Jones G, Ding C et al. The natural history of cartilage defects in people with knee osteoarthritis. Osteoarthritis Cartilage. 2008; 16:337-342.

doi:10.1016/j.joca.2007.07.005.

9. Samuels J, Krasnokutsky S, Abramson SB. Osteoarthritis: a tale of three tissues. Bull NYU Hosp Jt Dis. 2008; 66:244e 50.

10. Briot K, Audran M, Cortet B et al. Vitamin D: skeletal and extraskeletal effects recommendations for good practice. Presse Med. 2009; 38(1):43-54.

11. Ovesen L, Andersen R, Jakobsen J. Geographical differences in vitamin D status, with particular reference to European countries. Proc Nutr Soc. 2003; 62(4):813821.

12. Ross AC, Manson JE, Abrams SA, Aloia JF, Brannon PM, Clinton SK et al. The 2011 report on dietary reference intakes for calcium and vitamin D from the Institute of Medicine: what clinicians need to know. J Clin Endocrinol Metab. 2011;96:53-8.

13. Bergink AP, Uitterlinden AG, Leeuwen JP, Buurman CJ, Hofman A, Verhaar JA et al. Vitamin D status, bone mineral density, and the development of radiographic osteoarthritis of the knee: the Rotterdam Study. J Clin Rheumatol. 2009; 15:230-237. doi:10.1097/RHU.0b013e3181b08f20.

14. Altman R, Asch E, Bloch D, Boil G, Borestein D, Brandt K, Cheristy W, Cooke TD, Greenwald R, Hochberg M et al. Development of criteria for classification and reporting of osteoarthritis of the knee. Arthtitis Rheum 1986; 29:1039-1049.

15. Goula T, Kouskoukis A, Drosos G, AS, Ververidis A, Valkanis C, Zisimopoulos A, Kazakos K. Vitamin D status in patients with knee or hip osteoarthritis in a Mediterranean country. J Orthopaed Traumatol. 2015; 16:35-39.

16. Heidari B, Heidari P, Tilaki KH. Association between serum vitamin D deficiency and knee osteoarthritis. International Orthopaedics (SICOT). 2011;35:16271631. DOI 10.1007/s00264-010-1186-2.

17. Cao Y, Winzenberg T, Nguo K, Lin J, Jones G, Ding C. Association between serum levels of 25-hydroxyvitamin $\mathrm{D}$ and osteoarthritis: a systematic review. Rheumatology (Oxford). 2013;52:1323-34.

18. Bergink AP, Uitterlinden AG, Van Leeuwen JP, Buurman CJ, Hofman A, Verhaar JA, Pols HA. Vitamin D status, bone mineral density, and the development of radiographic osteoarthritis of the knee: the Rotterdam Study. J Clin Rheumatol 2009; 15(5):230-237.

19. Breijawi N, Eckardt A, Pitton MB, Hoelzl AJ, Giesa M, von Stechow D, Haid F, Drees P. Bone mineral density and vitamin $\mathrm{D}$ status in female and male patients with osteoarthritis of the knee or hip. Eur Surg Res. 2009; 42(1):1-10.

20. Nawabi DH, Chin KF, Keen RW, Haddad FS. Vitamin D deficiency in patients with osteoarthritis undergoing total hip replacement: a cause for concern? J Bone Joint Surg Br. 2010; 92(4):496-499.

21. Chaganti RK, Parimi N, Cawthon P, Dam TL, Nevitt MC, Lane NE. Association of 25-hydroxyvitamin D with prevalent osteoarthritis of the hip in elderly men: the osteoporotic fractures in men study. Arthritis Rheum. 2010; 62(2):511-514.

22. Ding C, Cicuttini F, Parameswaran V, Burgess J, Quinn S, Jones G. Serum levels of vitamin D, sunlight exposure, and knee cartilage loss in older adults: the Tasmanian older adult cohort study. Arthritis Rheum 2009; 60(5):1381-1389. 
23. Kwan Tat S, Lajeunesse D, Pelletier JP, Martel-Pelletier J. Targeting subchondral bone for treating osteoarthritis: what is the evidence? Best Pract Res Clin Rheumatol. $2010 ; 24: 51-70$. 